\title{
A preclinical animal model for evaluating the sealing capacity of covered stent grafts in acute vessel perforation
}

\author{
Alper Öner ${ }^{1,3^{*}} \mathbb{0}$, Caroline Moerke ${ }^{1}$, Anne Wolff ${ }^{1}$, Sabine Kischkel ${ }^{2}$, Wolfram Schmidt ${ }^{2}$, Niels Grabow ${ }^{2}$ \\ and Hüseyin Ince ${ }^{1}$
}

\begin{abstract}
Background: Percutaneous coronary intervention is among the most common therapeutic interventions in cardiology. This procedure may, however, be associated with a rare, though life-threatening complication: acute coronary perforation (CP). CP is primarily treated using covered stents, which are made of bare metal stents with a polytetrafluoroethylene (PTFE) or polyurethane coating. These stents' major limitations include higher rates of thrombus formation and restenosis. Hence, there is a still unmet need for new stents regarding their design and composition. Or, to test new covered stent designs, the rabbit iliac artery has become the best-established animal model. This study sought to present a preclinical animal approach designed to test covered stents that are utilized following vessel perforation.
\end{abstract}

Methods: The animal experiments were performed using New Zealand white rabbits, each weighting $3.5-4.5 \mathrm{~kg}$. The animal models described herein relied on the three most common clinical causes for CP, such as guidewire-induced, balloon catheter bursting, and device oversizing. Moreover, the sealing capacity of covered stent grafts was assessed for each of these models by means of angiography.

Results: We herein report a rabbit iliac artery perforation model using three different types of vessel perforation that closely mimic the clinical setting, such as guidewire-induced, balloon catheter rupture, and device oversizing. Using the same rabbit iliac perforation model, we additionally assessed the sealing capacity of a covered stent graft for each model.

Conclusions: The novel rabbit iliac artery perforation models, as described in this report, represent promising animal testing approaches. While their setting is very similar to the real-life context encountered in humans, all three models are based on an animal model that is ideally suited for evaluating the sealing capacity and performance of new medical devices for humans.

Keywords: Coronary perforation, Covered stent, Stent design, Guidewire, Balloon catheter, Rupture, Oversizing, Rabbit iliac artery model

*Correspondence: Alper.oener@med.uni-rostock.de

${ }^{3}$ Medizinische Klinik I im Zentrum für Innere Medizin (ZIM), Ernst-Heydemann-Str. 6, 18057 Rostock, Germany

Full list of author information is available at the end of the article

\section{Background}

One of the most common therapeutic procedures in cardiology is percutaneous coronary intervention, whose realizations have significantly increased in recent years [1]. Coronary perforation $(\mathrm{CP})$ is a rare but potentially life-threatening complication, with an incidence of $0.1 \%$ $3.0 \%$ and a mortality rate exceeding $20 \%[2,3]$. Known

c) The Author(s) 2020. This article is licensed under a Creative Commons Attribution 4.0 International License, which permits use, sharing, adaptation, distribution and reproduction in any medium or format, as long as you give appropriate credit to the original author(s) and the source, provide a link to the Creative Commons licence, and indicate if changes were made. The images or other third party material in this article are included in the article's Creative Commons licence, unless indicated otherwise in a credit line to the material. If material is not included in the article's Creative Commons licence and your intended use is not permitted by statutory regulation or exceeds the permitted use, you will need to obtain permission directly from the copyright holder. To view a copy of this licence, visit http://creativecommons.org/licenses/by/4.0/. The Creative Commons Public Domain Dedication waiver (http://creativecommons.org/publicdomain/zero/1.0/) applies to the data made available in this article, unless otherwise stated in a credit line to the data. 
CP predictors include age, female gender, complex lesions, as well as chronic total occlusion interventions or atherectomies [2, 4]. Proximal perforations are typically caused by balloons or devices, while more distal perforations are often produced by guidewires exiting the vessel lumen [5].

Although various approaches to treat $\mathrm{CP}$ exist, the standard method consists of using covered stents. Before covered stents were approved in the early 1990s, more than half of the patients underwent emergency cardiac surgery, which incurred a much higher mortality rate [3]. Covered stents are usually made of bare metal stents with a polytetrafluoroethylene (PTFE) or polyurethane coating. These stents display a $90 \%$ success rate for the treatment of perforation $[2,6]$. Their limitations, especially in case of bulky PTFE-covered stents, include significantly higher rates of thrombus formation and restenosis, compared to regular stents $[6,7]$.

Hence, new developments are still needed to improve both the design and composition of covered stents. To test new covered stent designs, the rabbit iliac artery model has become one of the best-established animal models, due to its close resemblance to human coronary arteries $[8,9]$.

In this study, we have presented a preclinical animal approach designed to test covered stents after vessel perforation, based on the three most common clinical causes of vessel perforation: guidewire-induced, balloon catheter bursting, and device oversizing.

\section{Methods}

\section{Animals and overall preparations}

All animal experiments were performed according to the German animal protection guidelines that have been approved by the local animal care and use committee (7221.3-1-045/19). New Zealand white rabbits (Charles River Laboratories, Ecully, France) were employed, each of which displayed a body weight of $3.5-4.5 \mathrm{~kg}$. This specific parameter ensured the carotid artery had an adequate diameter, which is essential to avoid tearing the artery upon insertion of the $4 \mathrm{Fr}$ introducer sheath (Terumo, Leuven, Belgium). All animals were constantly kept at a temperature of $21{ }^{\circ} \mathrm{C}$; humidity of $65 \%$ was maintained with a 12-h day and 12-h night rhythm, according to EU directive 2010/63/EU. Prior to the procedure, the animals were anesthetized by means of a subcutaneous injection in the neck, which consisted of a ketamine/xylazine mixture (50 mg ketamine hydrochloride [bela-pharm $\mathrm{GmbH}$, Vechta, Germany] and $5 \mathrm{mg}$ xylazine hydrochloride [Rompun 2\%, Bayer Healthcare $\mathrm{GmbH}$, Leverkusen, Germany]) per kg body weight. After $20 \mathrm{~min}$, the unconscious state of the animal was deep enough to begin shaving the throat and initiate the anesthetic infusion consisting of the ketamine-xylazine mixture $50 \mathrm{mg}$ ketamine and $5 \mathrm{mg}$ xylazine per kg body weight added to a $100-\mathrm{mL}$ sodium chloride $(\mathrm{NaCl})$ infusion bag; Freeflex $100 \mathrm{~mL} \mathrm{NaCl}$ 0.9, Fresenius Kabi, Bad Homburg, Germany], via the outer ear vein (26 G permanent intravenous catheter, BD Neoflon, Becton-Dickinson, Heidelberg, Germany). Throughout the experiment, the rabbit's eyes were kept hydrated with eye gel (Vidisic, Bausch \& Lomb, Berlin, Germany). Vital parameters, including pulse and oxygen saturation, were checked upon using a pulse oximeter (Nellcor, OxiMax N-65, Inspiration Medical GmbH, Bochum, Germany). Next, the animal was placed in a supine position on the operation table. Its body temperature was held at a constant $37{ }^{\circ} \mathrm{C}$ using a heating map (VetiCare, Vianen, Netherlands), and its supine position was fixed using towel rolls and leucoplast tape (BSN Medical, Hamburg, Germany).

\section{Surgical procedure-access to the carotid artery}

The left carotid artery was exposed through a lateral skin incision of approximately $5 \mathrm{~cm}$ in length, which was meticulously placed $1 \mathrm{~cm}$ beneath the midline of the neck. After the subcutaneous tissue was dissected, the internal jugular vein became visible, lying lateral to the tracheal ring. To expose the carotid artery and vagus nerve, an incision was made in between the tracheal ring and internal jugular vein. The jugular vein, which was handled very carefully, was fixed to the surrounding tissue using a surgical hook, and it was then cautiously removed from the operating side. Bleeding was controlled by means of manual compression and cauterization. Then, the carotid artery was dissected, isolated, and verified upon by Doppler sonography (Handydrop Pro, Elcat $\mathrm{GmbH}$, Wolfratshausen, Germany), before being entwined with a 3-0 Prolene suture thread (Ethlicon, Johnson \& Johnson, Norderstedt, Germany) at its most distal and proximal parts. The most distal thread was used to dilate the carotid artery so as to facilitate the puncture. The proximal thread was required for fixation, anchoring, and positioning of the carotid artery, as well as for its final ligation after removing the introducer sheath. The puncture was made using a 20-G Seldinger cannula (Braun, Melsungen, Germany), which faced downward to prevent any puncture of the posterior wall of the carotid artery. After successful artery puncture, a 0.014-in. coronary guidewire (6 Fr Radiofocus Introducer Set, Terumo, Leuven, Belgium) was advanced through the lumen of the Seldinger cannula and carotid artery. After removing the Seldinger cannula, the distal and proximal threads were pulled up to prevent any hemorrhage during the change and insertion of the $4 \mathrm{Fr}$ introducer sheath over the 0.014 -in. coronary guidewire. The introducer sheath 
was pushed approximately $3-4 \mathrm{~cm}$ into the carotid artery and fixed using suture threads.

\section{Surgical procedure-perforation and stent implantation} To prevent thrombus formation, 500 international units (IU) heparin (Ratiopharm GmbH, Ulm, Germany) were injected intra-arterially, via the introducer sheath, before inserting the guidewire (ASAHI SION blue, ASAHI INTECC, The Hague, Netherlands). Under angiographic guidance (Ziehm Vario 3D, Ziehm Imaging $\mathrm{GmbH}$, Nürnberg, Germany), and with the Accupaque 350 contrast medium (GE Healthcare, Braunschweig, Germany) diluted 1:1 with isotonic $\mathrm{NaCl}$ (Fresenius Kabi, Bad Homburg, Germany), the guidewire was advanced from the carotid artery to the proximal femoral artery and iliac artery. The guidewire's tip was J-shaped to better cross the aortic arch and reach the descending aorta. The angle to reach the descending aorta from the left carotid artery may sometimes be very steep, and even with the J-shaped wire, we were just unable to pass it. To overcome this difficulty, the wire was guided through the aortic valve and into the left ventricle, turned into a loop, and then, sent back with the blood flow along the aortic arch into the descending aorta. The wire loop was dismantled using careful pulling movements. After angiographic evaluation of the vessel composition and iliac artery localization, the setting of the perforation was prepared. For the perforation via guidewire, a 0.014-in. Confianza PRO 12 guidewire (ASAHI INTECC, The Hague, Netherlands) was inserted, in addition to the ASAHI SION blue guidewire. The Confianza PRO 12 guidewire displays a longer and stiffer tip $(20 \mathrm{~cm}$ vs. $3 \mathrm{~cm}$ for the ASHAI SION blue) and is thus better suited for performing vessel perforation. The vessel perforation was made by further movements of the Confianza PRO 12 guidewire against the distal iliac artery wall, with the vessel perforation then verified by angiography. The second option for achieving vessel perforation was carried out by overdilation and subsequent bursting of a balloon catheter (Emerge Monorail 3.0/15 mm, Boston Scientific, Marlborough, Massachusetts, USA). The balloon catheter was overdilated at $24 \mathrm{~atm}(\mathrm{RBP}=14 \mathrm{~atm})$. The next approach designed to mimic the third clinical cause of vessel perforation was carried out using a device that was oversized for the distal iliac artery $(4.5 / 12 \mathrm{~mm}$ balloon catheter, TREK, Abbott, Santa Clara, CA, USA). In addition, the oversized balloon catheter was overdilated at 24 atm until it bursted. Covered stents, which were $2.5 / 15 \mathrm{~mm}$ in size (Papyrus, Biotronik, Buelach, Switzerland), were quickly placed over the perforation site using an inflation device and an average dilation at $9 \mathrm{~atm}$ for $2 \mathrm{~s}$ (overdilation 1:1.1) (basixCOMPAK, Merit Medical, Utah, USA). Successful sealing of the perforation was checked via angiography. Then, the introducer sheath was removed, the carotid artery was ligated, and the incision was closed. The survival of the animal was monitored for $15 \mathrm{~min}$ after sealing the perforation. Then, the animal was gently euthanized by an intravenous injection of pentobarbital (300 mg per kg body weight, Release, WDT, Garbsen, Germany). After the animal had died, the stents were explanted and rinsed with isotonic $\mathrm{NaCl}$. Then, they were fixed in $4 \%$ neutral-buffered formalin (Süsse Labortechnik GmbH, Gudensberg, Germany).

\section{Results}

\section{Rabbit iliac artery perforation models}

Access to the iliac artery was obtained by surgical puncture of the left carotid artery (Fig. 1). To mimic the three

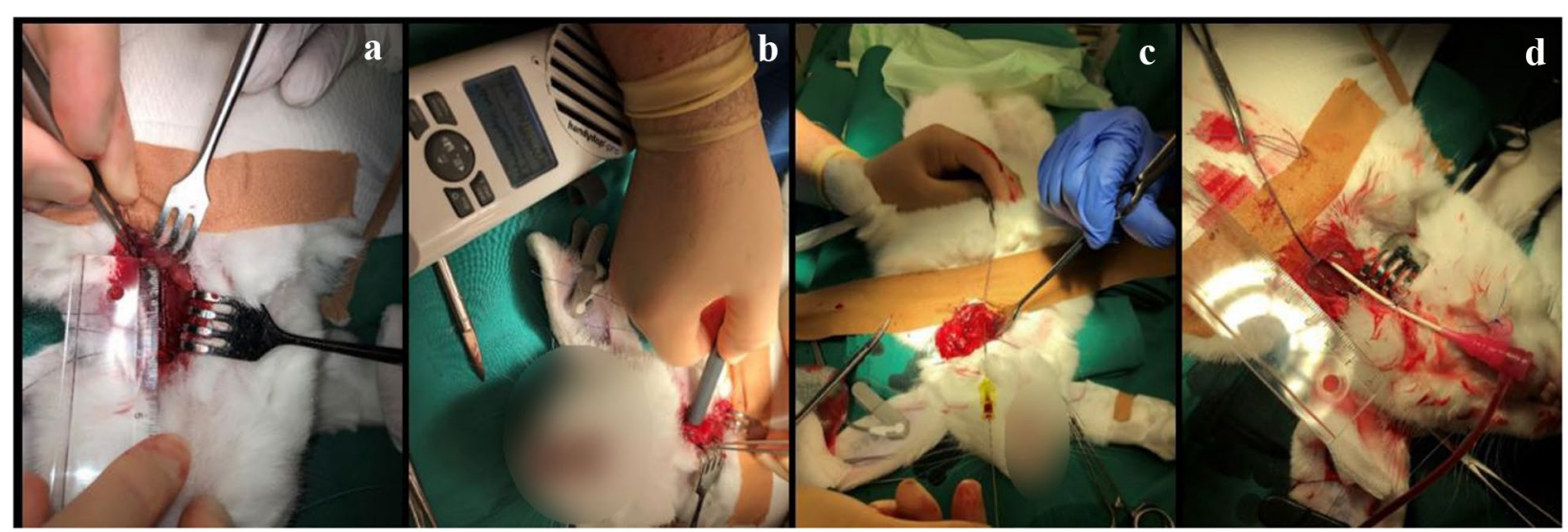

Fig. 1 Surgical preparation of the left carotid artery of the New Zealand white rabbit for cardiac intervention. a Dissected, isolated, and fixed carotid artery. $\mathbf{b}$ Verification of the artery by Doppler sonography. $\mathbf{c}$ Puncture of the carotid artery by a Seldinger cannula and induction of the 0.014 -in. coronary wire. $\mathbf{d}$ Fixation of the inserted 4-Fr introducer sheath 
most common clinical causes of vessel perforation during percutaneous coronary intervention, the rabbit iliac artery was injured using a guidewire, overdilation along with the bursting of a balloon catheter, and insertion of an oversized device.

During the guidewire-induced vessel perforation, a cavity spilling of contrast media extravasation was clearly visible on angiography (Fig. 2a). After placing a covered stent graft (Fig. $2 \mathrm{~b}$ ) on the perforation site, the leakage was staunched (Fig. 2c).

For the second approach to achieving vessel perforation by means of overdilation along with the bursting of a balloon catheter, the explosion of the balloon catheter (Fig. 3a) resulted in a massive artery injury and blood leakage (Fig. 3b). This rupture was fixed by implantation of three covered stent grafts (Fig. 3c-f).

In the third method designed to attain vessel perforation by means of an oversized device, a $4.5 \times 12 \mathrm{~mm}$ balloon catheter was inserted into the iliac artery (Fig. 4a). To intensify the perforation, the oversized balloon catheter was overdilated and slightly moved proximally (Fig. 4b) until its bursting (Fig. 4c). Massive extravasation of contrast media was the indicative of vessel perforation (Fig. 4d). After the first covered stent implantation (Fig. 4e), the extravasation of contrast media (Fig. 4f) was still visible. However, following a second covered stent implantation (Fig. 4g), the perforation was sealed, with no contrast media leakage detected upon angiography (Fig. 4h).

The covered perforation was monitored for another $15 \mathrm{~min}$, with the animal still alive and the perforation sealed during this time period. After the animals were euthanized, their arteries were explanted and checked again for vessel sealing by liquid flushing. For all three clinically relevant vessel perforation methods, an extended hematoma was visible within the surrounding tissues after the bleeding caused by vessel perforation (Fig. 5a). Concerning the second approach, the artery was significantly enlarged after inducing vessel perforation via balloon catheter overdilation with a $3.0 / 15 \mathrm{~mm}$ balloon catheter (Fig. 5b).

\section{Discussion}

In this study, we have described in detail a novel approach for testing the sealing capacity of covered stent grafts in an in vivo artery perforation model. To our knowledge, this is the first study reporting on a rabbit iliac artery perforation model with vessel perforation by guidewire, balloon catheter, and oversized device, in addition to the perforation's sealing with a covered stent graft.

The rabbit iliac model for stent implantation has been well established and is now accepted for comparing new experimental stent grafts versus conventional stents. This can essentially be explained by the similar dimensions of rabbit iliac arteries and human coronary arteries. Another standard animal model for the preclinical evaluation of endovascular devices is the porcine coronary artery model. However, this model exhibits several limitations, such as a higher granulomatous inflammatory reaction, rapid growth rate, and high body weight potential. In addition, these animals' housing conditions are more laborious and rather expensive, compared to those of rabbits [9-11].

Recently, Taavitsainen et al. [12] published a rabbit aorta perforation model. In regard to this paper, it must, however, be mentioned that the authors punctured the aorta by means of a 2 -mm biopsy punch after revealing the aorta through a midline abdominal incision. These authors succeeded in sealing the perforation with a newly developed covered stent graft. Essentially,

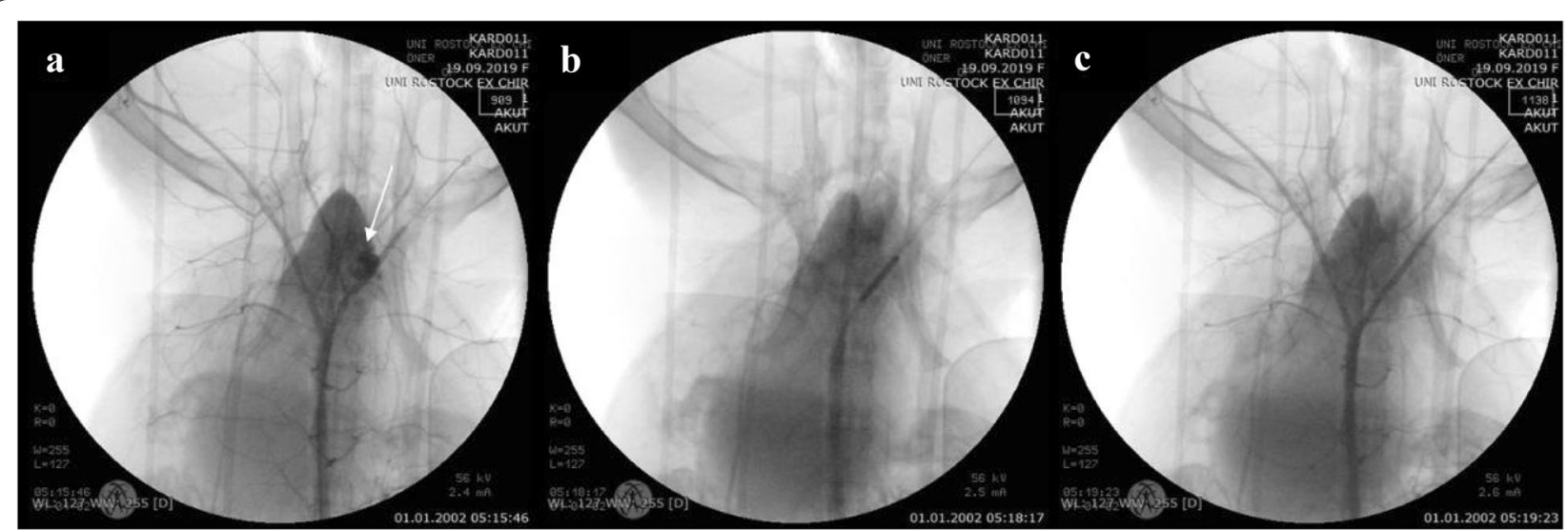

Fig. 2 Angiography of the iliac artery perforation via guidewire. a Cavity filling with blood after the vessel was injured with the Confianza PRO 12 guidewire. $\mathbf{b}$ Placing of a covered stent graft over the perforation site. $\mathbf{c}$ Verification of the leakage being sealed following stent implantation 


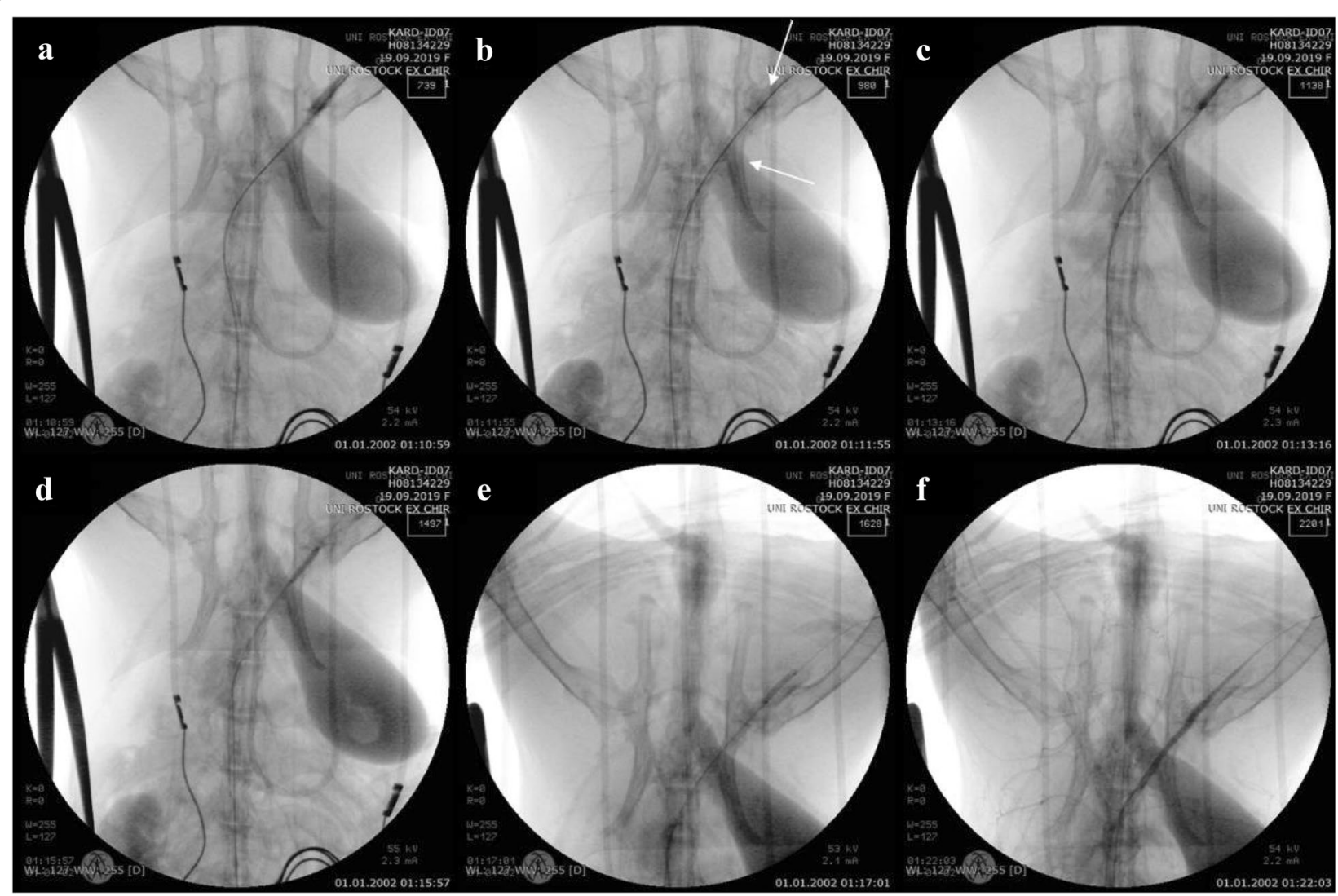

Fig. 3 Angiography of the iliac artery perforation by overdilation and the bursting of a balloon catheter. a The burst of overdilated balloon catheter. b Leakage of blood out of the ruptured vessel. Implantation of the (c) first, (d) second, and (e) third covered stents. $\mathbf{f}$ Verification of the leakage being sealed after stent implantation

surgically exposing the aorta after carotid artery catheterization, via surgical preparation of the carotid artery for the 6-Fr introducer sheath, proves to be very risky and dangerous for the animal. This invasive method, which is also very complicated, turns out to be a quite complex surgery with a high mortality risk.

Detailed methods have similarly been published that compare stent grafts within the scope of an atherosclerotic model in the rabbit iliac artery [11]. Conversely, our models of the iliac artery perforation using a guidewire, balloon catheter, and oversized device are all less invasive and not as dangerous. In addition, it must be stressed that our approaches fully reflect the clinical situations encountered in routine practice.

Thus, covered stent grafts must be analyzed in terms of their sealing capacity in regard to vessel perforation, as well as in terms of their performance concerning endothelization rates, inflammatory reactions, thrombosis, and restenosis formation after implantation. Long-term patency rates are deemed poor, particularly for conventional PTFE-covered stents [6, 7]. This further emphasizes the imperative need for new developments and appropriate testing models. 


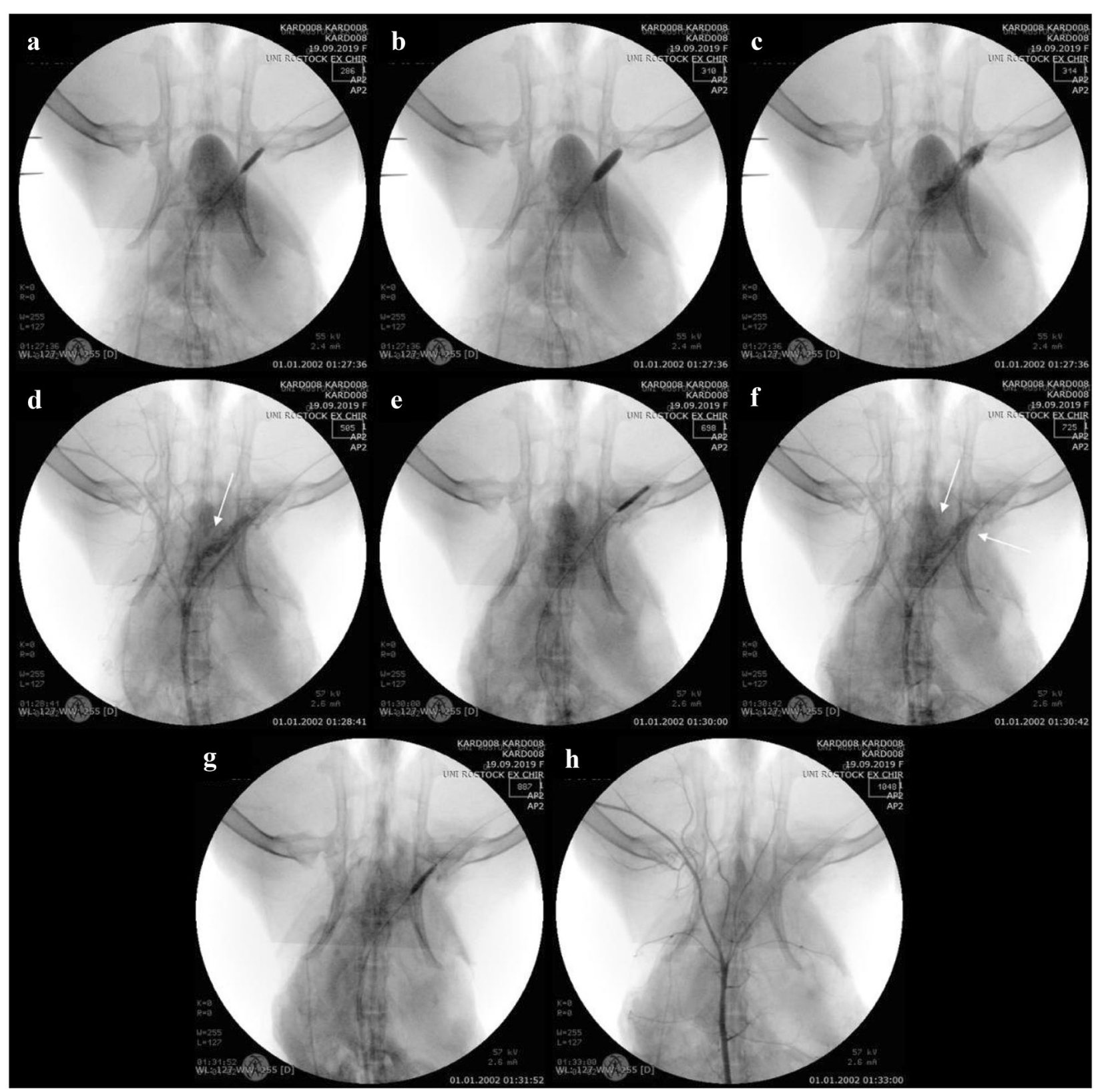

Fig. 4 Angiography of the iliac artery perforation by overdilation and the bursting of an oversized balloon catheter. a Placing and dilatation of the oversized balloon catheter. $\mathbf{b}$ Dislocation of the balloon catheter after overdilation. $\mathbf{c}$ The burst oversized balloon catheter. $\mathbf{d}$ Extravasation of contrast media after vessel perforation. e First covered stent implantation. $\mathbf{f}$ Leakage of blood from the ruptured vessel after first stent implantation. $\mathbf{g}$ Second covered stent implantation. $\mathbf{h}$ Verification of the leakage being sealed after stent implantation

To end, we would like to further emphasize the prerequisite of having appropriate animal models for biomedical research. To be appropriate, an animal model must first of all be relevant, meaning that a phenomenon to be studied in the animal must be as close as possible to the phenomenon that is encountered in humans. The models presented herein appear to fulfill these requirements. Accordingly, we assume that these novel approaches may play a catalytic role in our search for superior stent grafts. 


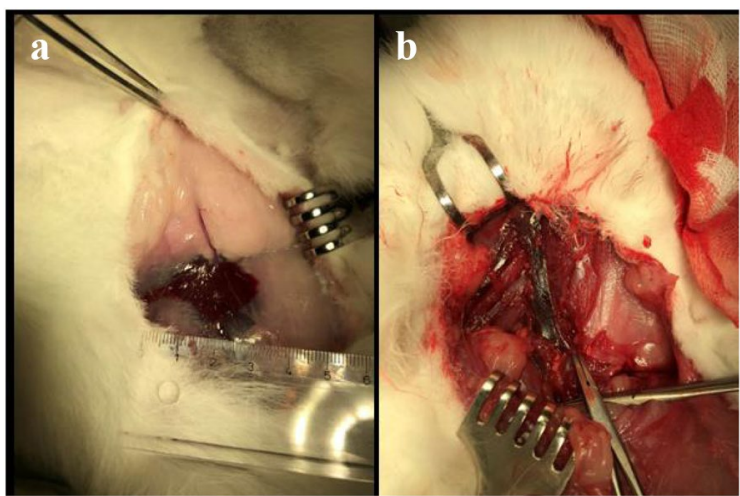

Fig. 5 Explantation of the stents. a Hematoma and $\mathbf{b}$ enlarged artery after vessel perforation via overdilation and the bursting of a balloon catheter

\section{Conclusions}

Based on these herein reported rabbit iliac artery perforation models, we present testing scenarios that nearly replicate the clinical situations encountered in routine practice, using an animal model that is suitable for evaluating the sealing capacity and performance of new medical devices for humans.

\section{Abbreviations}

CP: Coronary perforation; IU: International units; $\mathrm{NaCl}$ : Sodium chloride; PTFE: Polytetrafluoroethylene.

\section{Acknowledgements}

We would like to thank Prof. Brigitte Vollmar for enabling us to use the anima operation theater at the core facility of the Rudolf-Zenker-Institute of Experimental Surgery (University Medical Center Rostock).

\section{Authors' contributions}

$A O ̈, N G$ and $\mathrm{HI}$ designed the experiments. AÖ performed the experiments. $C M, A W, S K$ and WS prepared and assisted in the experiments. AÖ and CM performed data analysis, data interpretation and wrote the manuscript. All authors read and approved the final manuscript.

\section{Funding}

Financial support by the Federal Ministry of Education and Research (BMBF) within "RESPONSE - Partnership for Innovation in Implant Technology" is gratefully acknowledged. Open access funding provided by Projekt DEAL.

\section{Availability of data and materials}

The datasets used and/or analyzed during the current study are available from the corresponding author on reasonable request.

\section{Competing interests}

The authors declare that they have no competing interests.

\section{Author details}

${ }^{1}$ Department of Cardiology, Rostock University Medical Center, Rostock, Germany. ${ }^{2}$ Institute for Biomedical Engineering, Rostock University Medical Center, Rostock, Germany. ${ }^{3}$ Medizinische Klinik I im Zentrum für Innere Medizin (ZIM), Ernst-Heydemann-Str. 6, 18057 Rostock, Germany.

Received: 15 July 2020 Accepted: 20 July 2020

Published online: 29 July 2020

\section{References}

1. Werner N, Nickenig G, Sinning JM. Complex PCI procedures: challenges for the interventional cardiologist. Clin Res Cardiol. 2018;107:64-73.

2. Nagaraja V, Schwarz K, Moss S, Kwok CS, Gunning M. Outcomes of patients who undergo percutaneous coronary intervention with covered stents for coronary perforation: a systematic review and pooled analysis of data (published online ahead of print, 2019 Dec 18). Catheter Cardiovasc Interv. 2019. https://doi.org/10.1002/ccd.28646.

3. Romaguera R, Waksman R. Covered stents for coronary perforations: is there enough evidence? Catheter Cardiovasc Interv. 2011;78:246-53.

4. Patel VG, Brayton KM, Tamayo A, et al. Angiographic success and procedural complications in patients undergoing percutaneous coronary chronic total occlusion interventions: a weighted meta-analysis of 18,061 patients from 65 studies. JACC Cardiovasc Interv. 2013;6:128-36.

5. Lemmert ME, van Bommel RJ, Diletti R, et al. Clinical characteristics and management of coronary artery perforations: a single-center 11-year experience and practical overview. J Am Heart Assoc. 2017;6:e007049.

6. Al-Mukhaini M, Panduranga P, Sulaiman K, Riyami AA, Deeb M, Riyami MB. Coronary perforation and covered stents: an update and review. Heart Views. 2011;12:63-70

7. Guttmann OP, Jones DA, Gulati A, et al. Prevalence and outcomes of coronary artery perforation during percutaneous coronary intervention. Eurolntervention. 2017;13:e595-601.

8. Nakazawa G, Nakano M, Otsuka F, et al. Evaluation of polymer-based comparator drug-eluting stents using a rabbit model of iliac artery atherosclerosis. Circ Cardiovasc Interv. 2011;4:38-46.

9. lqbal J, Chamberlain J, Francis SE, Gunn J. Role of Animal Models in Coronary Stenting. Ann Biomed Eng. 2016;44:453-65.

10. Nakazawa G, Finn AV, Ladich E, et al. Drug-eluting stent safety: findings from preclinical studies. Expert Rev Cardiovasc Ther. 2008;6:1379-91.

11. Lee JM, Lee J, Jeong $\mathrm{H}$, et al. Development of a rabbit model for a preclinical comparison of coronary stent types in-vivo. Korean Circ J. 2013;43:713-22.

12. Taavitsainen J, Tarvainen S, Kuivanen A, et al. Evaluation of biodegradable stent graft coatings in pig and rabbit models. J Vasc Res. 2020;57:65-75.

\section{Publisher's Note}

Springer Nature remains neutral with regard to jurisdictional claims in published maps and institutional affiliations.

Ready to submit your research? Choose BMC and benefit from:

- fast, convenient online submission

- thorough peer review by experienced researchers in your field

- rapid publication on acceptance

- support for research data, including large and complex data types

- gold Open Access which fosters wider collaboration and increased citations

- maximum visibility for your research: over $100 \mathrm{M}$ website views per year

At BMC, research is always in progress.

Learn more biomedcentral.com/submissions 